$\underline{\underline{p}}$ 国

\title{
Numerical analysis of transcritical carbon dioxide compression cycle: a case study
}

\author{
Mohammad Mehdi Keshtkar * \\ Associate Professor, Department of Mechanical Engineering, Islamic Azad University, Kerman, Iran \\ *Corresponding author E-mail: mkeshtkar54@yahoo.com
}

\begin{abstract}
This study deals with thermodynamic investigation of a refrigeration compression cycle with carbon dioxide refrigerant and two stage compression. In this paper, the effect of intercooler in the two-stage compression system at different pressures of gas cooler is investigated. In addition, the performance of one stage compression cycle and two-stage compression cycle are compared and eventually, the performance of system is investigated under the influence of the change of variables such as gas cooler pressure, isentropic efficiency of the compressors, the intercooling rate between the two stages of compression, the refrigerant gas cooler outlet temperature is examined. Due to evaporation temperature in the evaporator $\left(-10^{\circ} \mathrm{C}\right)$ and refrigeration capacity $(\mathrm{kW})$ results show that the coefficient of performance in the two-stage compression with intercooler is increased compared to the single-stage compression cycle.
\end{abstract}

Keywords: Thermodynamic Analysis; Transcritical; Carbon Dioxide; Two-Stage Compression; Intercooler; Gas Cooler.

\section{Introduction}

In the beginning of the twentieth century carbon dioxide (R744) was widely used as refrigerant in air conditioning and refrigeration system of ships and other industries. Alexander Twinning was first to patent carbon dioxide as refrigerant in 1850. By 1940, it was the peak of the use of carbon dioxide as refrigerant, but the emergence of halocarbon refrigerants in 1940 led to a lack of interest in the use of natural refrigerants such as ammonia, carbon dioxide and sulfur dioxide. The main reason for the rapid growth in the use of halocarbon refrigerants was a reduction in carbon dioxide refrigeration capacity of the ships that crossed the tropics but ammonia was used in large scale industries. Due to the emergence of environmental problems of halocarbon refrigerants (CFC) which was identified in 1980, the industry began to search for alternative materials. Gustav Lorentzen believed that carbon dioxide refrigeration system could be used again. In this regard, a typical car air conditioning system with carbon dioxide cooling was built by Lorentzen and Paterson in 1992. According to research conducted in recent years, attention to carbon dioxide as a refrigerant has risen. Carbon dioxide has very low ODP and GWP and among natural refrigerants such as ammonia, hydrocarbons (Propane, butane and isobutane), it was introduced as the best option. Because it is not as toxic as ammonia and it is not flammable like hydrocarbons. In recent years, the use of natural refrigerants often as a substitute for halocarbon refrigerants is taken into consideration but due to the problems, it has never been considered a primary option. However, due to the development of cooling systems and creating new software for the thermodynamic properties of carbon dioxide and the introduction of different models, the efficiency of the system has increased. One excellent example is micro-channel heat exchangers which reduce the cost of system. Using the technology, the dimensions of carbon dioxide refrigeration system has become several times smaller than conventional systems with the same capacity and efficiency [1]. Carbon dioxide refrigerant is currently used in two types of refrigeration cycle. The refrigerant can be used in transcritical cycle as one stage or two-stage compression. The use is mainly in commercial refrigeration and air conditioning equipment in cars to reduce GWP. The refrigerant can also be used in cascade cycle that consists of a combination of two simple cycles. In this type of refrigerant cycle, carbon dioxide is used in low temperature cycle and the evaporator temperature is between -30 to $-50{ }^{\circ} \mathrm{C}$ and the condenser temperature is between -10 to $-30^{\circ} \mathrm{C}$. This cycle is used in large refrigeration industries. Common problems associated with the refrigerant are providing the necessary driving force in the compressor and high thermal load created due to refrigerant thermodynamic properties of carbon dioxide. This means that even with the use of low-capacity systems, a lot of heat is wasted by the cycle. Cecchinato et al. [2] conducted a thermodynamic and optimal assessment of a two-stage carbon dioxide transcritical cycle. In this study, several different cycles including a cycle with one stage compression, a cycle with two stage compression associated with a gas cooling circuit were analyzed. The effect of internal heat transfer between different flows of refrigerant in the whole cycle, the impact of internal heat exchanger and external cooling were evaluated with attention to isentropic efficiency of the compressors. Kim et al, [3] demonstrated that using an internal heat exchanger reduced the irreversibility in the process of refrigerant expansion. They also proved that the use of internal heat exchangers reduces the output temperature of the liquid refrigerant of cooler gas, which will be followed by an increase in COP. The use of the internal heat exchanger is especially effective in improving cycle performance so that lower temperatures will not create bubbles in the expansion valve inlet and also lead to the complete evaporation of refrigerant in the compressor inlet which can be useful to prevent mechanical damage to the compressor. They proved that the use of internal heat exchangers in R744 system is required. Arora et al [4] in 2011 designed a refrigerant system in 
which the waste heat of the gas cooler of transcritical compression refrigeration system with carbon dioxide was used to launch a single-effect absorption cooling system of lithium bromide-water. They observed that the system in combined mode compared to the compressed mode, has better performance so that for specific conditions, the cooling capacity of the combined system was greater than the compressed cooling cycle. Coefficient of performance and efficiency of the second law of combined cycle in the same conditions compared with the density cycle increased 14.2 and $3.67 \%$ respectively. Keshtkar [5] investigated effect of degrees of subcooling and superheating based on thermoeconomic optimization in two stage-cascade refrigeration system by using R717 and R744 as refrigerants. At the another works, Keshtkar et al. [6], [7] carried out a multi-objective optimization of cooling water package based on exergetic, economic and environmental analysis (3E) employing the non-dominated sorting genetic algorithm. Keshtkar et al. [8] investigated the optimization of a two stage-cascade refrigeration system (TS-CRS), based on exergetic, economic, environmental, and sensitive analysis (3ES). R134a and R744 are considered as the refrigerants of high and low temperature circuits, respectively.

In the present work, the thermodynamic performance of carbon dioxide refrigeration system with two-stage compression and the use of internal heat exchanger at different pressures of gas cooler and refrigerant outlet temperature of the gas cooler were investigated. In addition, the isentropic efficiency of compressors, different values of intercooling between two compression stages and the effect of the presence or absence of internal heat exchanger in the one-stage and two-stage transcritical cycles was investigated.

\section{The basis of the performance of a tran- scritical refrigeration cycle with r744 re- frigerant}

Although the thermodynamic properties of R744 refrigerant cause that its use in a conventional refrigeration cycle lead to low amount of energy efficiency it is considered as an efficient solution to reduce global warming and eco-friendly refrigerants. When carbon dioxide refrigerant is compared with conventional refrigerants, the most notable characteristic of R744 refrigerant is its low critical temperature $\left(30.9^{\circ} \mathrm{C}\right)$. Refrigerants that have a critical temperature lower than room temperature (such as the tropical regions), condensation of steam can not be done with heat loss and it is placed in transcritical part between the two subcritical and supercritical areas. Figure (1) shows the difference between the two cycles with R744 and R134a refrigerants. In common R134a system, after compression, phase change (steam - liquid) is created in condenser, but there is no phase change in the gas cooler in the R744 transcritical cycle.

This is a unique feature for R744 refrigeration cycle. Gas cools above the critical temperature in a gas cooler instead of condenser and it is also noteworthy that the thermodynamic properties of supercritical R744 quickly change during the cooling process in the cooler gas. Gas cooler design in these systems is very important and challenging. Heat loss in the gas cooler occurs through a process of constant pressure. During this stage, the temperature is reduced between the inlet and outlet of cooler gas. In Figure 2 the structure of tracscritical cycle in the one-stage compression cycle and in Figure 3, the structure of tracscritical cycle in the two-stage compression cycle is shown which is investigated in this study. Compressor, expansion device, evaporator and performance are similar to the conventional subcritical system.
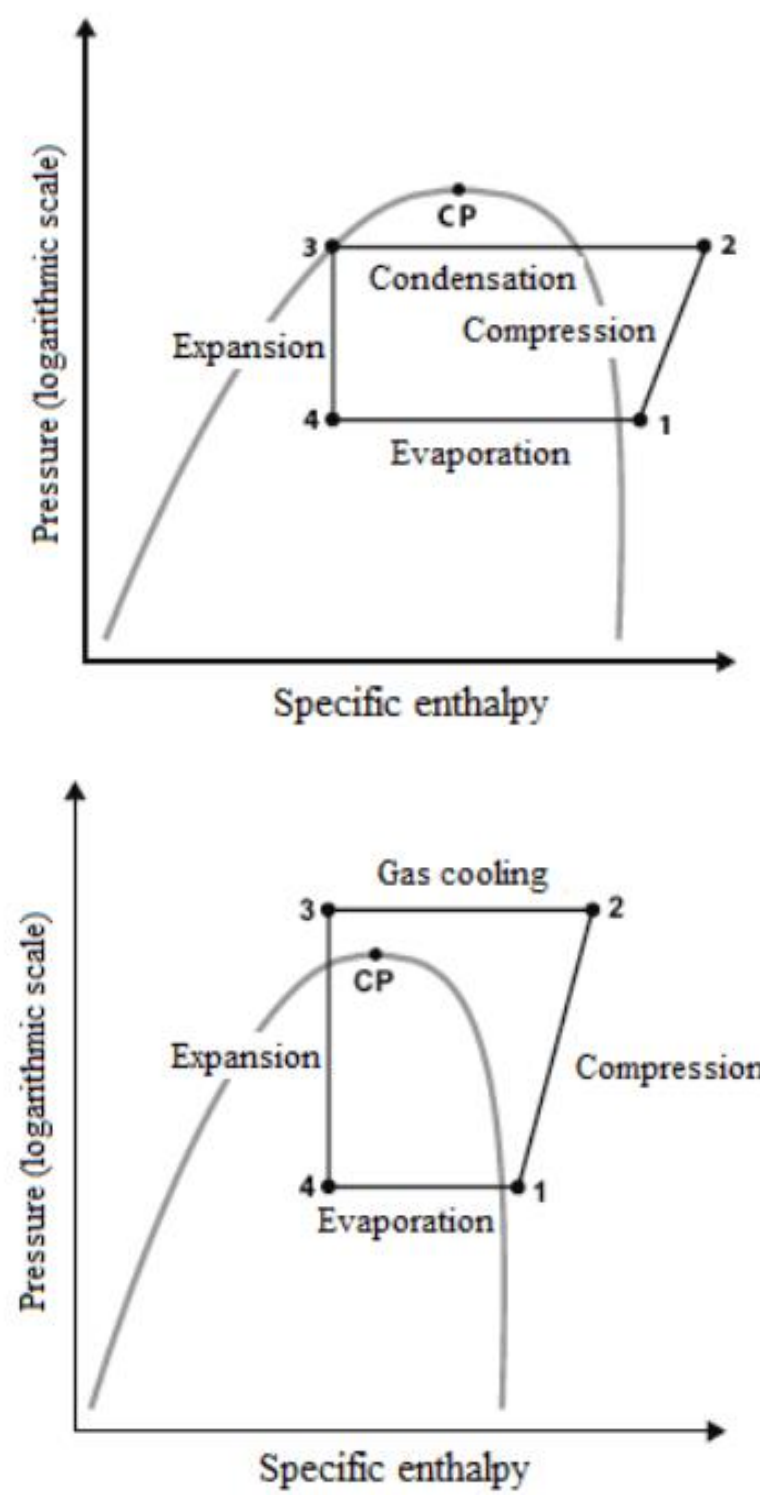

Fig. 1: Enthalpy Pressure Diagram for the Subcritical Cycle with R134a Refrigerant (Left Hand) and the Transcritical Cycle with R 744 Refrigerant (Right Hand).

Notable in the carbon dioxide transcritical cycle is the temperature difference of 50 to $80^{\circ} \mathrm{C}$ between the evaporator and condenser. Such a temperature difference creates operational problems that various methods have been proposed to solve this problem. One of these methods is multistage compression. Although this method increases the cost of the initial installation compared to the singlestage compression, instead, using multi-stage compression resolves problems caused by high temperature differences. Using this method also reduces the need for compressor power. Transcritical cycle has a high output compressor temperature (about $100{ }^{\circ} \mathrm{C}$ ) which is due to the need for high pressure in the gas cooler (approx. 95bar). Another solution to improve the efficiency of the transcritical cycle with R744 refrigerant is the use of two-stage compression with cooling exchanger between the two stages of compression. Reducing the output temperature of the refrigerant from the second stage compressor and creating lower temperature output gas cooler increases the refrigeration capacity in the system. 


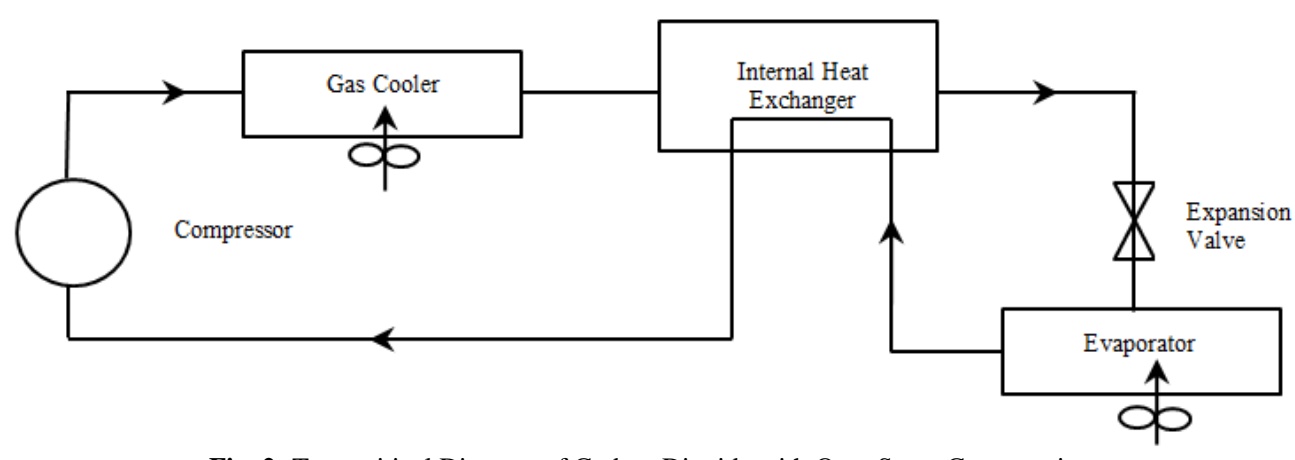

Fig. 2: Transcritical Diagram of Carbon Dioxide with One- Stage Compression.

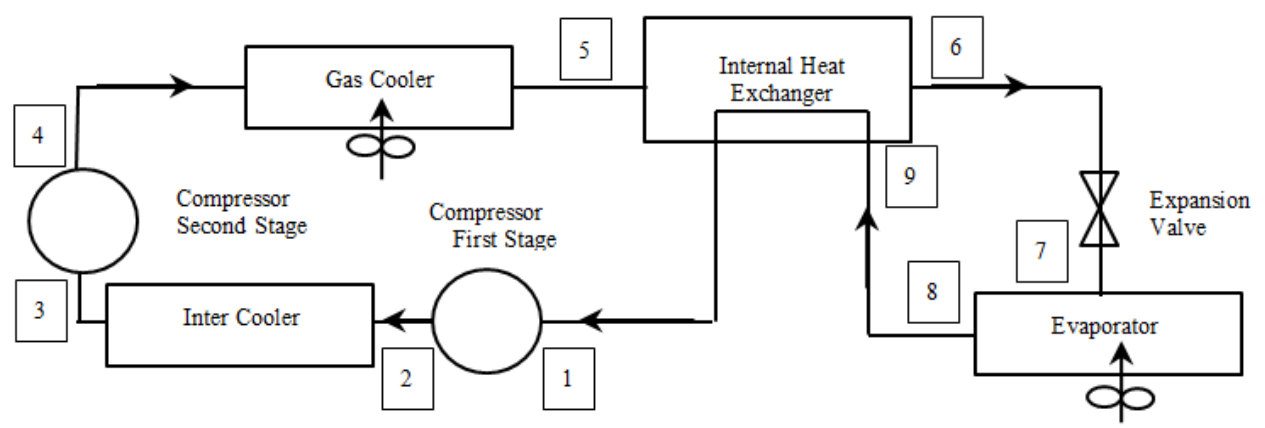

Fig. 3: Transcritical Diagram of Carbon Dioxide with Two- Stage Compression.

The intercooler exchangers first reduce high temperature of refrigerant compressor output of the first stage by reducing the flow of ambient air. As intercooler in refrigeration systems somewhat reduce the refrigerant temperature, they can cause added costs. In transcritical refrigeration system with carbon dioxide, intercooler cannot reduce the required power for congestion and it even increases it. The main reason for the use of this converter is that it reduces the outlet temperature of the compressor. In reciprocating compressors, the high-output temperature ruins the oil and reduces the life of compressor discharge valve.

In two-stage compression, the mean optimum pressure between suction pressure and discharge pressure (gas cooler pressure) is obtained by equation (1):

$$
P_{\text {NTT }}=\sqrt{P_{\text {Disch arge }} \times P_{\text {Suction }}}
$$

\section{Results}

\subsection{Statement of the problem and numerical simulation}

For the thermodynamic investigation of the transcritical two-stage compression cycle, a computational code written in the EES application was used [9], [10]. This study compares the thermodynamic properties of transcritical cycle with one and two-stage compression. Then the effects of parameters such as refrigerant temperature output of gas cooler, isentropic efficiency of compressors, the presence or absence of internal heat exchanger (SGHX), mean pressure between the two compression stages, the intercooler value, compressors consumption and energy consumption have been investigated. Operating parameters to simulate operating conditions are shown in Table 1 [11-14]. In addition, using parameters obtained by Ozgur [15], the mean optimized pressure by equation (1) is estimated.
Table 1: Parameters Used in the Refrigeration System

\begin{tabular}{ll}
\hline Parameter & Value \\
\hline Evaporative Temperature & $-10^{\circ} \mathrm{C}$ \\
Refrigeration Capacity & $5 \mathrm{~kW}$ \\
Isentropic Efficiency of Compressors & $60 \%$ \\
Gas cooler Pressure & $95 \mathrm{bar}$ \\
Gas cooler Temperature Outlet & $32^{\circ} \mathrm{C}$ \\
Inter cooler Temperature & $25^{\circ} \mathrm{C}$ \\
Internal Heat Exchanger Efficiency & $50 \%$ \\
Intermediate Pressure & $5013 \mathrm{kPa}$ \\
First Step Compressor Temperature Outlet & $56{ }^{\circ} \mathrm{C}$ \\
Superheating in Evaporator & $5{ }^{\circ} \mathrm{C}$ \\
Superheating in Suction Line & $1{ }^{\circ} \mathrm{C}$ \\
\hline
\end{tabular}

The thermal efficiency of the internal heat exchanger states the quality of the efficiency of the heat exchange by temperature difference between the suction line and liquid. Providing a general guide to the amount of thermal efficiency for an internal heat exchanger (gas suction heat exchanger) is difficult. Usually the amount of efficiency between 2.0 and 5.0 is acceptable. Points shown in Figure 3 on the diagram P-h (Figure 4) for the two- stage cycle is marked. On point 1 , gas suction by compressor in the first stage and the output (point 2) is the gas output from compressor and input to the cooling exchanger of heat exchanger. The output refrigerant of the compressor in this converter cools a bit. This temperature reduction in the second stage reduces the temperature of refrigerant at the outlet of the gas cooler and increases cooling capacity. Table 1 shows a number of data obtained from the simulation system. 


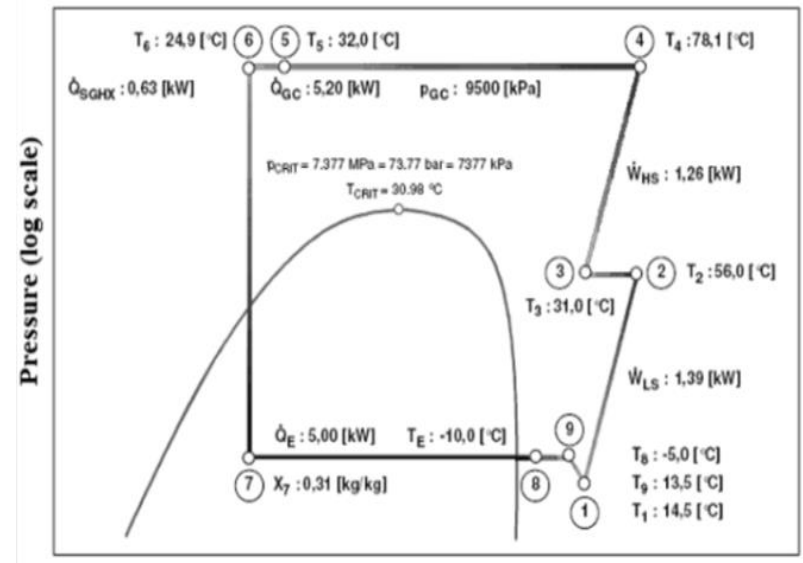

Enthalpy (log scale)

Fig. 4: Diagram P- H, Transcritical Two-Stage Refrigeration Cycle with Carbon Dioxide.

The true gas enthalpy in superheated part at the outlet of the compressor in the first stage (low pressure stage of LS ) and the second compression stage (high pressure stage of HS) is obtained by equations (2) and (3) [16]:

$h_{2}=\frac{h_{2 i r}-h_{1}}{\eta_{i s L S}}+h_{1}$

$h_{4}=\frac{h_{4 i r}-h_{2}}{\eta_{\text {isHS }}}+h_{3}$

Where $\eta_{i s}$ is the entropic efficiency of compressors and $h_{i s}$ is the isentropic enthalpy at the outlet of the compressor. Changes of thermodynamic properties using the formula for the control volume are calculated for each part of the cycle. Using the control volume to determine the amount of energy is done regardless of the kinetic energy and potential heat interaction in the system boundary, which is equal to total enthalpy. Relations related to the thermodynamic cycle of the analysis are as follows [17-19]:

a) $q_{e}=\left(h_{1}-h_{7}\right)$

b) $q_{g c}=\left(h_{4}-h_{5}\right)$

c) $q_{\text {int }}=\left(h_{2}-h_{3}\right)$

d) $\quad w=\frac{h_{4 i s}-h_{3}}{\eta_{i s} H S}+\frac{h_{2 i s}-h_{1}}{\eta_{i s} L S}$

e) $\quad \mathrm{COP}=\frac{q_{e}}{W \operatorname{comp}}=\frac{h_{1}-h_{7}}{\frac{h_{4 i s}-h_{3}}{\eta_{i s} H S}+\frac{h_{2 i s}-h_{1}}{\eta_{i s} L S}}$

\subsection{Results}

Figure 5 shows the effect of the internal heat exchanger use in single-stage and two-stage compression cycle on increasing the pressure of gas cooler function. As can be seen, two-stage transcritical cycle performance is higher than single-stage cycle. It can also be observed that with increasing pressure, the efficiency difference of the cycles is almost constant. It is shown that with increasing pressure at 95 bar single-stage cycle efficiency is increased with an amount equal to two- stage cycle without heat exchanger. Single-stage cycle is less sensitive to the presence or absence of heat exchanger. Based on the values of the coefficient of performance, it is observed that the two-stage compression cycle with an internal heat exchanger is more efficient than the cycle without internal heat exchanger.

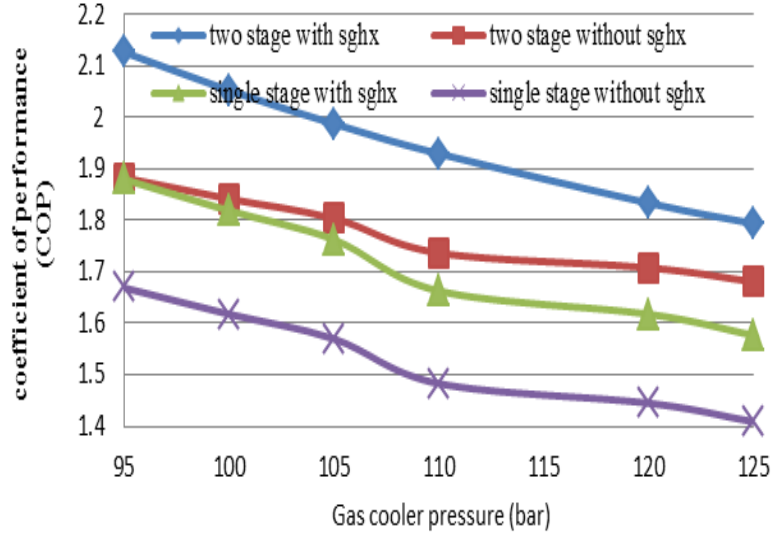

Fig. 5: The Effect of an Internal Exchanger (SGHX) on Cycle Performance.

Figure (6) shows the impact of the outlet refrigerant temperature of gas cooler on the performance of both types of cycles. It is observed that by reducing the outlet refrigerant temperature of the gas cooler, the performance coefficient of the system increases. This primarily increases the cooling capacity of the cycle. When the temperature of the refrigerant liquid entering the evaporator is reduced, consequently, more refrigeration capacity is created in the evaporator. Analysis of Figure 6 shows that for the two transcritical cycles, by reducing the temperature range of $6{ }^{\circ} \mathrm{C}$ in the gas cooler output, the coefficient of performance is increased. It is also clear that the two-stage compression cycle performance is $15 \%$ more than single-stage cycle. It can be seen that the coefficient of performance is higher at 95 bar pressure compared to 105 bar pressure due to the lower compression ratio of the system.

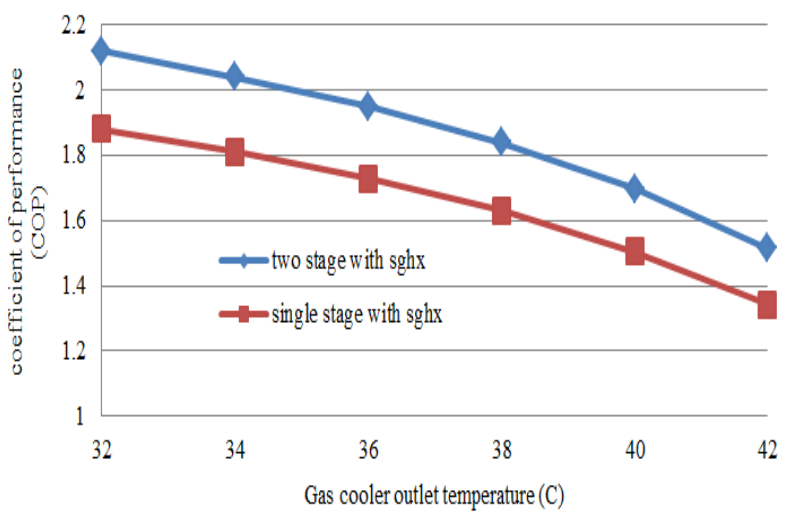

Fig. 6: Effect of Gas Cooler Output Temperature on the Efficiency of the Cycle.

Figure (7) shows improving the performance coefficient of the transcritical cycle by increasing isentropic efficiency of the compressors at gas cooler pressure between 95 to 105bar. Isentropic efficiency of compressors (including motor electric losses) depends on the system compression ratio. By increasing the compression ratio, isentropic efficiency becomes lower. It can be seen that with increasing efficiency of compressors, coefficient of performance improves and therefore energy loss during congestion reduces. 


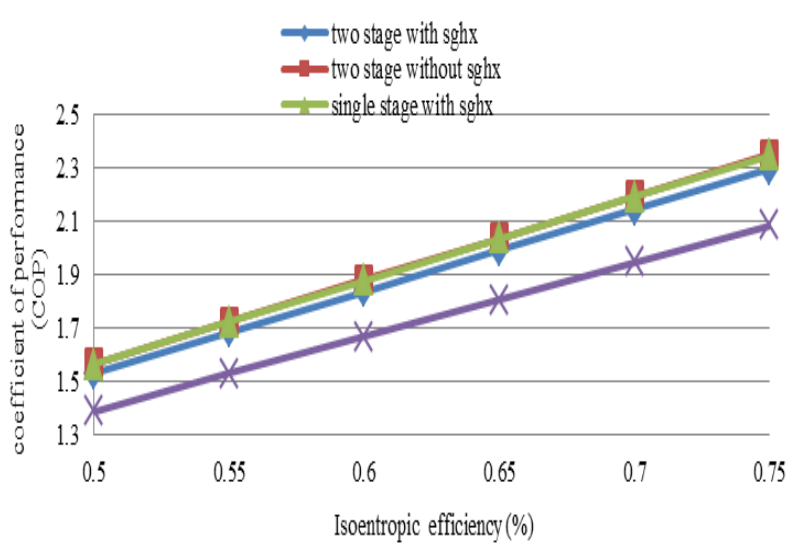

Fig. 7: The Effect of Isentropic Efficiency of Compressors on Cycle Performance.

Figure (8) shows the impact of the gas cooler pressure on the coefficient of performance of two transcrictical cycles. The determined optimal pressure in both cycles is related to the more favorable coefficient of performance of the cycle. Sudden changes in compressor discharge pressure may cause significant changes in the coefficient of performance of the system. The results show that the optimal high pressure in transcritical cycle for single-stage cycle in the operating conditions mentioned with heat exchanger is about 80 bar and for two-stage cycle with heat exchanger is 95 bar.

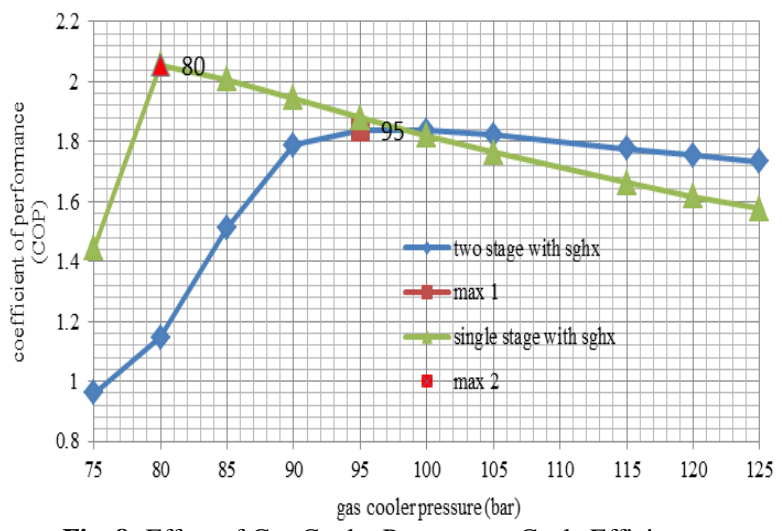

Fig. 8: Effect of Gas Cooler Pressure on Cycle Efficiency.

Figure 9 shows intermediate pressure effect on density performance of low pressure compressors and high pressure compressors. With medium increase of pressure, the compressor performance in the first stage increases and compressor performance of the second stage is reduced. It can be seen that regarding the desired cyclic conditions, optimum pressure is around 55 bar where the lowest density by the system is required.

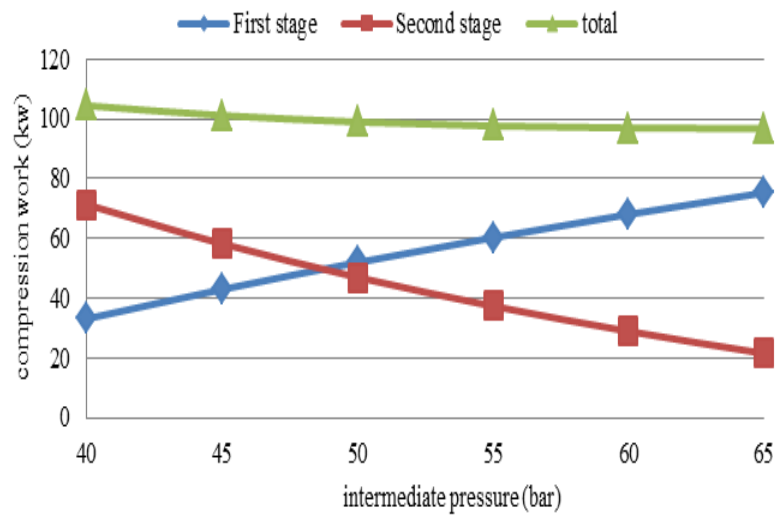

Fig. 9: Effect of Intermediate Pressure on the Work Done by the Compressors.

Figure 10 shows the effect of gas cooler pressure on energy consumption per day for both cycles. As expected, two- stage cycle has $11 \%$ less energy consumption than single-stage cycle making it a good alternative for systems with low electrical power consumption.

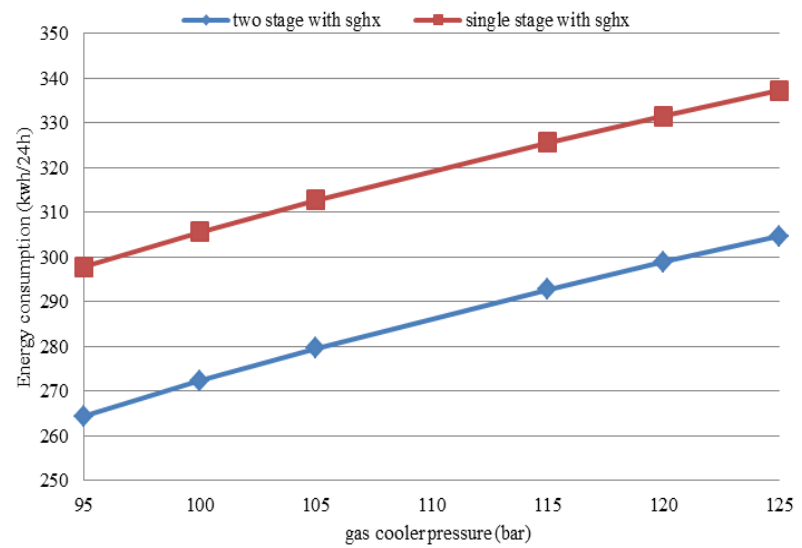

Fig. 10: The Impact of Gas Cooler Pressure on Energy Consumption for Both Transcritical Cycles.

Figure (11) shows performance coefficient change of two- stage cycle as the temperature difference created in the intercooler at different pressures of gas cooler. Finally, it was found that according to the operating parameters, it can be decided whether singlestage transcritical refrigeration system is appropriate or two-stage compression system.

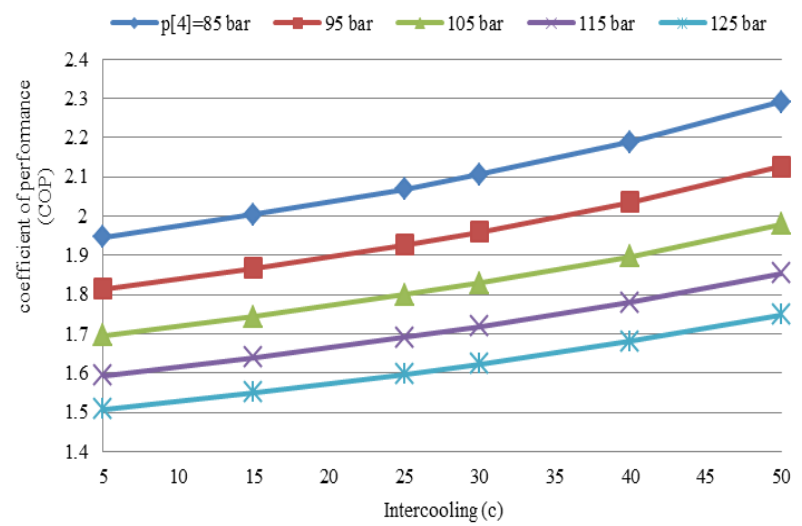

Fig. 11: The Effect of Temperature Difference Created by the Intercooler on the Coefficient of Performance of Two- Stage Cycle at Different Pressures.

\section{Conclusions}

Theoretically, transcritical cycle with R744 refrigerant has lower energy efficiency compared to conventional compression cycles. Developed analysis in this study showed that multi-stage system with internal exchanger increased energy efficiency is the best option. Since the amount of rejected heat between compression stages depends on the average pressure, a pressure optimal for this parameter is needed. It was observed that the amount of isentropic efficiency of compressors and gas cooler pressure are important parameters to achieve lower temperatures at gas cooler outlets and the coefficient of performance of the cycle. The ambient temperature is of course a determining factor for obtaining the reduced temperature. It was observed that according to the conditions of the desired cycle, the optimum pressure is about 55 bar where the lowest density is required by the whole system. It was also shown that the two- stage cycle consumes $11 \%$ less energy than a singlestage cycle. 


\section{Symboles}

\begin{tabular}{ll}
\hline$C O P$ & Coefficient of performance $(-)$ \\
\hline$h$ & Enthalpy, $\left(\mathrm{kJkg}^{-1}\right)$ \\
$\eta_{i s}$ & Isentropic efficiency, $(\%)$ \\
\hline
\end{tabular}

\section{References}

[1] N. Agrawal, S. Bhattacharyya, Exergy assessment of an optimized capillary tube-based transcritical $\mathrm{CO} 2$ heat pump system. Int.Journal of Energy Research, 5 (2009) 1536-1543.

[2] L. Cecchinato, M. Chiarello, M. Corradi, E. Fornasieri, S. Minetto, P. Stringari, Thermodynamic analysis of different two-stage transcritical carbon dioxide cycles. Int. Journal of Refrigeration, 32 (2009)1058-1067. https://doi.org/10.1016/j.ijrefrig.2008.10.001.

[3] M.H. Kim, J. Pettersen, C.W. Bullard, Fundamental Process and System Design Issues in CO2 Vapor Compression Systems, Progress in Energy and Combustion 30 (2004) 119-174. https://doi.org/10.1016/j.pecs.2003.09.002.

[4] A. Arora, N.K. Singh, S. Monga, O. Kumar, Energy and exergy analysis of a combined transcritical $\mathrm{CO} 2$ compression refrigeration and single effect $\mathrm{H} 2 \mathrm{O}-\mathrm{LiBr}$ vapour absorption system. Int. Journal
Exergy,
(2011)
42-49.

[5] M.M. Keshtkar, Effect of subcooling and superheating on performance of a cascade refrigeration system with considering thermoeconomic analysis and multi-objective optimization, Journal of Advanced Computer Science \& Technology, 5 (2) (2016) 42-47. https://doi.org/10.14419/jacst.v5i2.6217.

[6] M.M. Keshtkar, P. Talebizadeh, Multi-objective optimization of cooling water package based on 3Eanalysis: A case study, Journal of $\quad$ Energy, $134 \quad$ (2017) https://doi.org/10.1016/j.energy.2017.06.085.

[7] M.M. Keshtkar, Performance analysis of a counter flow wet cooling tower and selection of optimum operative condition by MCDMTOPSIS method, Applied Thermal Engineering, 114 (2017) 776784. https://doi.org/10.1016/j.applthermaleng.2016.12.043.

[8] M.M. Keshtkar, P. Talebizadeh, Multi-Objective Optimization of a R744/R134a Cascade Refrigeration System: Exergetic, Economic, Environmental, and Sensitive Analysis (3ES), Journal of Thermal Engineering, 5 (2017) 1840-1849.

[9] S.A. Klein, F.L. Alvarado, EES - Engineering Equation Solver, FChart Software, Middleton, 1995.

[10] Lorentzen, G. The use of natural refrigerants: a complete solution to the CFC/HCFC predicament. Int. Journal of Refrigeration, 18 (1995) 190-197. https://doi.org/10.1016/0140-7007(94)00001-E.

[11] K.B. Madsen, C.S. Poulsen, M. Wiesenfarth, Study of capillary tubes in a transcritical CO2 refrigeration system. Int. Journal of Refrigeration, $\quad 28 \quad$ (2005) 1212-1218. https://doi.org/10.1016/j.ijrefrig.2005.09.009.

[12] A.B. Pearson, Optimizing CO2 Systems. Proceedings of the 7th IIR Gustav Lorentzen Conference on Natural Working Fluids, Trondheim, Norway, 2006.

[13] C. Rohrer, Transcritical CO2 Bottle Cooler Development, Proceedings of the 7th IIR Gustav Lorentzen Conference on Natural Working Fluids, Trondheim, Norway, 2006.

[14] J.L.Yang, Y.T. Ma, S.C. Liu, Performance investigation of transcritical carbon dioxide two-stage compression cycle with expander.
Energy,
32
(2007)
237-245. https://doi.org/10.1016/j.energy.2006.03.031

[15] A.E. Özgur, The performance analysis of a two-stage transcritical $\mathrm{CO} 2$ cooling cycle with various gas cooler pressures, Int. Journal of Energy Research, 32 (2008) 1309-1315. https://doi.org/10.1002/er.1425.

[16] Y. Chen, J. Gu, The optimum high pressure for $\mathrm{CO} 2$ transcritica refrigeration systems with internal heat exchangers. Int. Journal of $\begin{array}{llll}\text { Refrigeration, } & 28 & \text { (2005) } & 1238-1249\end{array}$ https://doi.org/10.1016/j.ijrefrig.2005.08.009.

[17] N. Agrawal, S. Bhattacharyya, J. Sarkar, Optimization of two-stage transcritical carbon dioxide heat pump cycles. Int. Journal of Thermal Sciences, $46 \quad$ (2007) 180-187. https://doi.org/10.1016/j.ijthermalsci.2006.04.011

[18] M. Fatouh, M.E. Kafafy, Assessment of propane/commercial butane mixtures as possible alternatives to R134a in domestic refrigerators, Energy Conversion and Management, 47 (2006) 2644-2658 https://doi.org/10.1016/j.enconman.2005.10.018. 